Research Article

\title{
Traffic and Health among Commuters in Urban Bengaluru, Karnataka, India - An Exploratory Study
}

\author{
NR Ramesh Masthi', G Bharath' ${ }^{2}$, Afraz Jahan ${ }^{3}$ \\ ${ }^{1}$ Professor, ${ }^{2}$ Undergraduate Student, ${ }^{3}$ Tutor Cum Post graduate, Department of Community Medicine, Kempegowda Institute \\ of Medical Sciences, Banashankari II Stage, Bengaluru.
}

DOI: https://doi.org/10.24321/2455.7048.201916

I $\quad \begin{array}{llll}\mathbf{N} & \mathbf{F} & \mathbf{O}\end{array}$

\section{Corresponding Author:}

Afraz Jahan, Department of Community Medicine, Kempegowda Institute of Medical Sciences, Banashankari II Stage, Bengaluru.

E-mail Id:

dr.afrazjahan@gmail.com

Orcid Id:

https://orcid.org/0000-0002-3523-6860

How to cite this article:

Masthi NRR, Bharath G, Jahan A. Traffic and Health among Commuters in Urban Bengaluru, Karnataka, India - An Exploratory Study. Epidem Int 2019; 4(3): 27-33.

Date of Submission: 2019-09-19

Date of Acceptance: 2019-11-01
$\begin{array}{llllllll}\mathbf{A} & \mathbf{B} & \mathbf{S} & \mathbf{T} & \mathbf{R} & \mathbf{A} & \mathbf{C} & \mathbf{T}\end{array}$

Background: Vehicular emissions degrade the ambient air quality posing a major public health problem in cities across the world. Being stuck in traffic for long hours has been attributed with increased incidence of road rage, back pain, cramps, anxiety and depression.

Objectives: To find out the magnitude of health problems among daily commuters in traffic; To assess the effects of traffic on health of daily commuters.

Methods: A descriptive cross-sectional exploratory study was done in urban Bengaluru in the first half of 2018. The sample size was 506. The subjects should have been a resident of Bengaluru for a minimum period of one year, should have commuted with either one or more than one mode of transport within the city on a daily basis.

Results: Out of a total of 506 study subjects, 253 (50.0\%) were males and 253 (50.0\%) were females. The median (IQR) age of the subjects was $21(20,23)$ and age range was between $16-60$ years. The overall burden of one or more than one health problems observed due to traffic was 376 (74.3\%). The health problems attributed to traffic was 289 (57.11\%) subjects complained of body pain, 205 (40.5\%) mentioned physical exhaustion/ dehydration, 144 (28.5\%) allergies and 159 (31.4\%) respiratory problems.

Conclusion: One or more than one health problems was observed in more three forth of the subject due to commute in traffic. Body pain and physical exhaustion/ dehydration were the commonest health problems observed.

Keywords: Traffic, Health, Physical Exhaustion, Stress

\section{Introduction}

A common discussion among residents of Bengaluru, Karnataka, India is the time taken to reach a destination and the distance to be travelled, the reason simply being traffic. Bengaluru, also known as India's Silicon Valley contributes to $38 \%$ of India's total IT exports. ${ }^{1}$ Being the hub for technological companies, an exponential surge 
in migration of people coming from within and outside country leading to an alarming increase in the number of vehicles registered in the city has occurred. In the year 2019 , the number of registered vehicles was over 81 lakhs with a staggering 58 lakh private vehicles. ${ }^{2,3}$ Evidently, the number of vehicles plying on road has risen within the same limited geographical area. Another cause of concern is the type of vehicles plying and exhaust emissions. The consequence of this ever-increasing vehicle density is the traffic congestion and traffic jams leading to health issues.

Vehicular emissions degrade the ambient air quality posing a major public health problem in cities across the world. Long term exposure to vehicular emissions of particulate matter $<2.5 \mathrm{~mm}$ is known to cause severe respiratory problems. ${ }^{4}$ Karnataka State Pollution Control Board had noted that traffic and emission account for $62 \%$ of fine dust (<PM 2.5 dust) and proven to be harmful to lungs and blood. ${ }^{3}$ Being stuck in traffic for long hours has been attributed with increased incidence of road rage, accidents, physical exhaustion, back pain, cramps, neurological problems such as anxiety and depression. ${ }^{5-9}$ Statistics states, two people die every day due to road accidents. ${ }^{10}$ Studies have found that, increased traffic congestion can cause impaired cognitive development in children and have the potential to cause DNA methylation leading to gene damage. ${ }^{11,12}$

All the above factors influence the health of an individual. Hence, foreseeing the possible complications and preventing it at an earlier state becomes necessary. Available evidence on overall effects of traffic on health is limited.

\section{Objectives}

To find out the magnitude of health problems among daily commuters in traffic; to describe the socio-demographic profile of study subjects and to assess the effect of traffic on health of daily commuters.

\section{Materials and Methods}

An exploratory study was done on daily commuters in urban Bengaluru between first half of 2018. The sample size was calculated based on the pilot study prevalence of $45 \%$. Taking confidence level to be $95 \%$ and relative precision of $10 \%$, the sample size was 489 . It was rounded off to 500 . The subjects were selected through snowball technique. The first subject was selected through personal contacts of the interviewers, the next subject was selected through his contact and this sampling was followed until the required sample size was reached. The subjects should have been a resident of Bengaluru for a minimum period of one year, should have commuted with either one or more than one mode of transport within the city on a daily basis and had access to the internet and understood the English language. The operational case definition for daily commuters was: Four-wheeler and two-wheeler commuters should have self-driven the vehicle. While for bus, auto rickshaw and metro train the commuter must have been a passenger. An online questionnaire was used as a survey tool to measure the demographic characteristics and the health problems the commuters had associated with traffic. A separate depression, anxiety and stress scale also known as DASS-21 scale was used to analyse the mental health of the subjects. The DASS-21 questionnaire consists of a list of 21 questions to which the answers are given based on a grading scale from zero to three, where zero indicates that it never happened and three indicates often. The results were obtained after multiplying the final score with two. The grading for stress was as follows: normal $=0-14$, ild $=15-18$, moderate $=19-25$, severe $=26-33$ and extremely severe $=34+$; The grading for anxiety was: normal $=0-7$, mild $=8-9$, moderate $=10-14$, severe $=15-19$ and extremely severe $=20+$; The grading for depression was: normal $=0-9$, mild $=10-13$, moderate $=14-20$, severe $=21-27$ and extremely severe $=28+$.

Statistical Analysis: The data was analysed in R studio and $\mathrm{R}$ Commander Statistical Package. Descriptive statistics like mean and percentage was calculated to describe the data. Univariate and multivariate logistic regression was applied to look for association between traffic and health problems. Crude odds ratio, adjusted Odds ratio and $p$ value were also computed. The ethical clearance was obtained from the institutional ethical committee. Informed consent of the subjects was taken and confidentiality was maintained.

\section{Result}

Out of a total of 506 study subjects (An additional 6 subjects gave information and were included in the analysis), 253 (50.0\%) Males and females were equally represented. The median age of the subjects with interquartile range was 21 $(20,23)$ and age range was between $16-60$ years. Majority of the subjects 410 (81.2\%) belonged to the age group of 16 to 25 as depicted in Table 1 . Among the subjects, 44 (8.7\%) were doctors by occupation, 28 (5.5\%) were IT professionals, 18 (3.6\%) were engineers, 64 (12.6\%) were either business manager/ fitness trainer/freelancing/ lawyer/homemaker and 352 (69.6\%) were students.

$146(28.9 \%)$ subjects travelled less than 5 kms, 115 (22.7\%) travelled 5-10 kms, 112 (22.1\%) travelled 10-15 kms and 133 (26.3\%) travelled more than 15 kms. 230 (45.5\%) subjects spent less than half an hour in traffic in a day, 177 (35.0\%) half to 1 hour in a day, 72 (14.2\%) 1-2 hours in a day and 27 (5.3\%) more than 2 hours. Male subjects were predominately commuting in two or four wheelers, while female subjects predominately commuted via bus/ metro/auto rickshaw. The subjects using four wheelers were 165 (32.6\%), Two wheelers were 210 (41.5\%), Auto 
rickshaw 69 (13.6\%), Bus 184 (36.4\%) and Metro train 52 $(10.3 \%)$. Each of the subjects travelled in one or more of the above modes of transportation.

The overall burden of health problems observed due to traffic among subjects was 376 (74.3\%). The individual health problems attributed to traffic were mainly 289 (57.11\%) subjects complained of body pain, 205 (40.5\%) mentioned physical exhaustion/dehydration, 144 (28.5\%) allergies and $159(31.4 \%)$ respiratory problems. $23(85.2 \%) / 27$ subjects with more than 2 hours in traffic experienced body pain compared to $103(44.8 \%) / 230$ subjects who spent less than half an hour in traffic $(Z=-3.9728, p<0.05)$. Type of body pain: $136(47.1 \%)$ subjects experienced back pain, 115 (39.8\%) leg pain and 84 (29.1\%) had neck/shoulder pain.

Among subjects who drove four wheels, 106 (64.2\%) complained of one or other type of body pain with the most frequent being back pain 58 (47.2\%). Among the 210 subjects who drove two wheels, 125 (59.5\%) complained of one or more type of body pain the most common being back pain $65(52.0 \%)$. Similarly, back pain was the most frequent complaint in subjects using other modes of transportation.

Table 2, describes the association between body pain and socio demographic characteristic by Univariate Logistic Regression. It was observed that age group of 26-35 years, engineers by profession, more than half an hour spent in traffic, driving four wheelers were found to be statistically significant. Finally, to assess overall effect of traffic on health, the binary logistic regression model was applied. Body pain was the dependant variable. It was observed that only age group of $26-35$ years [AOR $=2.65(1.46$ 4.81), $p=0.001$ ] and time spent half to 1 hour [AOR=2.08
(1.38-3.11), $\mathrm{p}=<0.001]$; $1-2$ hours [AOR=3.35 (1.87-6.00), $p=<0.001]$ and $>2 h r s$ [AOR=6.00 (1.98-18.2), $p=0.001]$ in traffic were statistically significant.

$314(62.1 \%)$ subjects stated that they were involved in an incident of road rage once or more than once, of whom, 170 (54.1\%) were males and majority 246 (78.3\%) were in the age group of $16-25$ years. The association between road rage and demographic characteristic was assessed by Univariate Logistic Regression. It was observed that being in the age group of 26-35yrs (OR=1.79, $\mathrm{p}<0.04)$, male gender $(O R=1.55, p<0.01)$, and subjects driving two wheelers $(O R=1.55, p<0.01)$ were significant. Further on multivariate analysis, only subjects driving two wheelers were found significant $(O R=1.62, p<0.01)$. Among subjects commuting via own vehicle, $53.0 \%$ mentioned potholes and unnecessary speed breakers as a major factor promoting road rage. On the other hand, those travelling by bus/ metro/ auto rickshaw, $50.0 \%$ opined air pollution, $43.0 \%$ noise pollution and $40.0 \%$ facing reckless drivers as reasons promoting road rage.

Table I.Age and sex distribution of the subjects

\begin{tabular}{|c|c|c|c|}
\hline $\begin{array}{c}\text { Age } \\
\text { (in years) }\end{array}$ & Female & Male & Total \\
\hline $16-25$ & $216(85.4)$ & $194(76.7)$ & $410(81.0)$ \\
\hline $26-35$ & $26(10.3)$ & $44(17.4)$ & $70(13.8)$ \\
\hline $36-45$ & $8(03.2)$ & $12(04.7)$ & $20(4.0)$ \\
\hline$>46$ & $3(01.1)$ & $3(1.2)$ & $6(1.2)$ \\
\hline Total & $\mathbf{2 5 3 ( 1 0 0 . 0 )}$ & $\mathbf{2 5 3 ( 1 0 0 . 0 )}$ & $\mathbf{5 0 6 ( 1 0 0 . 0 )}$ \\
\hline
\end{tabular}

Figures in parenthesis indicate percentage.

Table 2.Association between body pain and socio demographic characteristic by univariate logistic regression

$(n=506)$

\begin{tabular}{|c|c|c|c|c|}
\hline \multirow[t]{2}{*}{ Variables } & \multicolumn{2}{|c|}{ Body pain } & \multirow{2}{*}{$\begin{array}{l}\text { Odds ratio } \\
(95 \% \text { C I) }\end{array}$} & \multirow[b]{2}{*}{$P$ value } \\
\hline & Present $(n=289)$ & $\begin{array}{l}\text { Absent } \\
(n=217)\end{array}$ & & \\
\hline \multicolumn{5}{|l|}{ Age } \\
\hline $16-25$ & $219(75.8)$ & $191(88.0)$ & - & - \\
\hline $26-35$ & $53(18.3)$ & $17(7.8)$ & 2.72 & $<0.001$ \\
\hline $36-45$ & $12(4.2)$ & $8(3.7)$ & 1.31 & 0.56 \\
\hline$>46$ & $5(1.7)$ & $1(0.5)$ & 4.36 & 0.18 \\
\hline \multicolumn{5}{|l|}{ Gender } \\
\hline Male & $143(49.5)$ & $110(50.7)$ & - & - \\
\hline Female & $146(50.5)$ & $107(49.3)$ & 1.05 & 0.78 \\
\hline \multicolumn{5}{|l|}{ Occupation } \\
\hline Students & $186(64.4)$ & $166(76.5)$ & - & - \\
\hline Doctors & $28(9.7)$ & $16(7.4)$ & 1.56 & 0.178 \\
\hline
\end{tabular}




\begin{tabular}{|c|c|c|c|c|}
\hline Engineers & $15(5.2)$ & $3(1.4)$ & 4.46 & 0.019 \\
\hline IT Professional & $20(6.9)$ & $8(3.6)$ & 2.23 & 0.063 \\
\hline Others & $40(13.8)$ & $24(11.1)$ & 1.49 & 0.155 \\
\hline $\begin{array}{c}\text { Time spent in Traffic } \\
\text { (In hours) }\end{array}$ & & & & \\
\hline$<1 / 2$ & $103(35.6)$ & $127(58.5)$ & - & - \\
\hline $1 / 2-1$ & $111(38.4)$ & $66(30.5)$ & 2.07 & $<0.001$ \\
\hline $1-2$ & $52(18.0)$ & $20(9.2)$ & 3.21 & $<0.001$ \\
\hline$>2$ & $23(8.0)$ & $4(1.8)$ & 7.09 & $<0.001$ \\
\hline Type of Vehicle* & & & & 0.024 \\
\hline Four-wheeler & $106(36.7)$ & $59(27.2)$ & 1.55 & 0.357 \\
\hline Two-wheeler & $125(43.3)$ & $85(39.2)$ & 1.18 & 0.095 \\
\hline Auto rickshaw & $33(11.4)$ & $36(16.6)$ & 0.64 & 0.09 \\
\hline Bus & $96(33.2)$ & $88(40.6)$ & 0.72 & 0.83 \\
\hline Metro & $29(10.0)$ & $23(10.6)$ & 0.94 & \\
\hline Exercise & & & & - \\
\hline No & $57(19.7)$ & $50(23.0)$ & - & 0.366 \\
\hline Yes & $232(80.3)$ & $167(77.0)$ & 1.22 & \\
\hline
\end{tabular}

Figures in parenthesis indicate percentage. *Multiple choice.

$6.9 \%$ of the subjects had a diagnosed medical condition like allergic rhinitis, cough, asthma, anxiety, keratoconus, sunburn, etc. and were advised to minimise travelling through traffic. 91 (17.98\%) subjects had habits such as drinking, smoking or drugs and $22(24.2 \%)$ experienced an increased urge in habits while stuck at traffic.

Overall, $42(8.3 \%)$ subjects were diagnosed to have stress using the DASS-21 scale, $26(5.1 \%)$ and $16(3.2 \%)$ subjects had mild and moderate stress respectively. $26(6.4 \%) / 407$ subjects who spent less than 1 hour in traffic complained of stress compared to $16(16.2 \%) / 99$ subjects who spent more than 1 hour, which was found to be statistically significant $(Z=-3.1612, p=0.001)$. Similarly, 118 (23.3\%) subjects were diagnosed to have anxiety using the DASS-21 scale, 41 (8.1\%), 56 (11.1\%), 17 (3.4\%) subjects had mild, moderate, and severe anxiety respectively. $44(19.1 \%) / 230$ subjects who spent less than half an hour in traffic complained of anxiety compared to $74(26.8 \%) / 276$ subjects who spent more than half an hour, which was found to be statistically significant $(Z=-2.0345, p=0.04)$. Overall, $94(18.6 \%)$ subjects were diagnosed to have depression using the DASS21 scale, $50(9.9 \%), 42(8.3 \%), 2(0.4 \%)$ had mild, moderate and severe depression respectively. $36(15.7 \%) / 230$ subjects who spent less than half an hour in traffic complained of depression compared to $58(21.0 \%) / 276$ subjects who spent more than half an hour. There was no statistical significance observed.

$253(50 \%)$ of the subjects felt traffic as a hindrance to maintaining their relationships and $350(69.2 \%)$ of the study subjects stated that traffic was taking away time from their social life.

\section{Discussion}

The most important health problem observed by daily commuters in traffic was body pain. A large number of subjects faced back pain compared to neck or leg pain. This can be attributed to the long hours of sitting in a vehicle while stuck at traffic. Body pain was also not dependent on the mode of transport, subjects travelling via two-wheeler/ auto rickshaw/ bus experienced pain similar to subjects travelling via four-wheelers or metro train. The reason can be multi factorial, two wheelers do not have back support, seats in auto rickshaw are not very comfortable in comparison to car and bus passengers travel more often standing than sitting.

Asthma, COPD, Upper and lower respiratory tract Infection are other health problems that can be attributed to traffic. Bengaluru is a city of high traffic, long term exposure of daily commuters to air pollution is a definite recipe for respiratory tract infections. There is a need for strong regulations that allow vehicles with acceptable emission standards to ply on the roads. Some of the most polluted cities are located in India. The annual particulate matter (PM2.5) quality ranged from 96.6 to 135.8 micrograms/cubic metre in different cities, way above the WHO recommendation of 10 micrograms/ cubic metre for fine particulate matter. ${ }^{13}$ Vehicular emission due to traffic is a significant cause for 
air pollution. $91 \%$ of the world's population lives in places where air quality exceeds WHO guideline limits. In terms of global disease burden, air pollution is the cause for over onethird of deaths from stroke, lung cancer, chronic respiratory disease and one-quarter of deaths from ischaemic heart disease. ${ }^{14}$ Increase in air pollution can cause worsening of an already existing lung pathology like asthma or chronic obstructive pulmonary disease or can stimulate allergic conditions like allergic rhinitis. ${ }^{15}$ Another cause of concern is the Bioaerosols (Bacterial contamination and fungal spores in the air) content. The average Bioaerosols content in Bengaluru city ranged between 64,000 colony forming units per cubic metre to $89,000 \mathrm{CFU} / \mathrm{m}^{3}$ and above the WHO recommendation of $10,000 \mathrm{CFU} / \mathrm{m}^{3} .{ }^{16}$ Bioaerosols combined with air pollution can lead to infections like Urinary Tract Infection, Bacteraemia, Allergies, etc. ${ }^{17}$ Studies done in London and USA states that the benefits of exercise are reversed on long term exposure to air-pollution. ${ }^{18}$ Another study of interest states that inhalation of smoke present in a high traffic zone is no different from that of effects of tobacco. ${ }^{18}$ Road rage was observed mainly in males and commuters who spent more time in traffic. Road rage anger or violence between drivers is often caused by difficult driving conditions. ${ }^{19}$

Apart from rash driving by fellow drivers and improper driving standards, there are other triggering factors for road rage like poor maintenance of roads, potholes, narrow two-way roads, unnecessary speed breaker, excessive honking causing noise pollution, dust and smoke from vehicle emissions. Additional factors contributing to road rage includes reckless driving especially by the cab and auto rickshaw drivers, pedestrians walking on roads, due to footpaths being completely occupied by vendors, driving with high beam lights, unnecessary breaking and domestic animals straying on roads. These factors not only promote road rage but eventually lead to accidents. Long hours in traffic and Road rage were attributed to placing people at a higher risk of attaining hypertension in Mumbai. ${ }^{20}$ Habits such as smoking/drinking/drugs were higher among subjects who spent more time in traffic. This can be due to the physical and mental stress that people face while stuck at traffic especially those who are returning back after working. There is a strong possibility of a psychological involvement where people find this habit as a way to destress themselves.

Studies from different settings in other countries observed that Stress, Anxiety and Depression were found to be higher among subjects who spent more time in traffic similar to observations of the present study. ${ }^{21-25}$ They are majorly due to psychological distress faced at traffic superadded by personal problems such as running late for a meeting, missing out on family occasions, personal relationship distress. Studies are ongoing linking Alzheimer's to time spent in traffic. ${ }^{26}$ Stress is known to cause various health problems such as tension headaches, heartburn, insomnia, increase the risk of heart disease, erectile dysfunction and fertility problems. ${ }^{21}$ Difficulties in maintaining normal social relationships were higher among subjects spending more time in traffic. This can be attributed to long hours spent in traffic, where a person is usually irritated and loses temper easily, disturbs harmony between couples especially among those working and have kids.

As urban cities are growing and expanding, there is urgent need to invest in traffic management across the country before it becomes a major public health problem. Better roads, integrated signalling of traffic junctions, investment in public transportation, encouraging people to use public transport, work from home, introducing vehicles having efficient pollution control, ergonomically designed vehicles, strictly adhering and following traffic rules are some of the measures that can be incorporated to minimize health problems due to traffic. Similarly, providing urban amenities in rural areas, development of the underdeveloped states and districts will discourage migration. Compulsory planting of tree saplings should also help.

\section{Conclusion}

About three forth of the subjects had one or more health problems due to commuting in traffic. Body pain and physical exhaustion/dehydration were the commonest health problems observed. Stress, anxiety and depression was observed among commuters spending long hours in traffic.

\section{Recommendation}

A larger study using random covering a wide geographical area and population is needed for generalization of the study results.

\section{Limitation}

The health problems observed was due to commute in traffic is as mentioned by the subjects and assumed to be true. There is no causal relationship. The burden of accidents due to driving in traffic was not part of the study. Snowballing technique will have its inherent bias of sampling and the result obtained may not be the true picture.

\section{Funding}

This research did not receive any specific grant from funding agencies in the public, commercial, or not-for-profit sectors.

\section{Conflict of Interest: None}

\section{References}

1. Bangalore will become the world's largest IT cluster by 2020. The Hindu. Cited 2019. Available from: https://www.thehindubusinessline.com/ info-tech/\%E2\%80\%98Bangalore-will-become- 
the-world\%E2\%80\%99s-largest-IT-cluster-by2020\%E2\%80\%99/article20909098.ece.

2. Philip C. Number of vehicles in Bengaluru more than doubles to 70 lakhs in 10 years -times of India. Cited 2018 Dec 22. Available from: https://timesofindia. indiatimes.com/city/bengaluru/number-of-vehicles-inbengaluru-more-than-doubles-to-70-lakh-in-10-years/ articleshow/60445747.cms.

3. Bengaluru closes in on Delhi, has 80 lakh vehicles. Cited 2019 April 15. Available from: https://www. deccanherald.com/city/top-bengaluru-stories/ bengaluru-closes-in-on-delhi-has-80-lakhvehicles-726305.html.

4. How bad is Bangalore air pollution and how can we deal with it? Cited 2018 Dec 22. Available from: https://medium.com/@selfishaltruist/how-bad-isbangalore-air-pollution-and-how-can-we-deal-withit-3a69a8070c5e.

5. Kaiser S, Furian G, Schlembach C. Aggressive behaviour in road traffic - findings from Australia. Transportation Research Procedia 2016; 14: 4384-92. [Google Scholar].

6. Sansone R, Sansone L. Road rage. What's driving it? PubMed Central 2010; 7: 14-8. [Google Scholar/ PebMed].

7. Smart R, Mann R. Is road rage a serious traffic problem. Traffic Injury Prevention 2010; 3: 183-9. [Google Scholar].

8. Steindl S, Kirby J. Road rage: Why normal people become harmful on the roads. Cited 2018 Aug 12. Available from: https://theconversation.com/roadrage-why-normal-people-become-harmful-on-theroads-60845.

9. The effects of traffic congestion. Cited 2018 Aug 13. Available from: https://getawaytips.azcentral.com/ the-effects-of-traffic-congestion-12304680.html.

10. Sharma M. 729 people lost their lives on the Bangalore roads in 2014. Cited 2018 Dec 22. Available from: https://sites.ndtv.com/roadsafety/729-people-losttheir-lives-on-the-bangalore-roads-in-2014-618/.

11. Sunyer J, Esnaola M, Alvarez-Pederol $M$ et al. Association between traffic related air pollution in schools and cognitive development in primary schools: A prospective cohort study. Plos Medicine 2015; 12(3): e1001792.24. Available from: researchgate.net/ publication/273153132_Association_between_TrafficRelated_Air_Pollution_in_Schools_and_Cognitive_ Development_in_Primary_School_Children_A_ Prospective_Cohort_Study. [Google Scholar/ PebMed].

12. Nawrot T, Adcock I. The detrimental health effects of traffic related air pollution. American Journal of Respiratory and Critical Care Medicine 2009; 179(7): 523-524. [Google Scholar/ PebMed].
13. Fifteen of the 20 most polluted cities in the world are in India. Cited 2019 April 29 May 8. Available from: https://www.thehindu.com/sci-tech/energy-and environment/fifteen-of-the-20-most-polluted-citiesin-the-world-are-inindia/article26440603.ece.

14. Air Pollution. Cited 2019 April 29. Available from: https://www.who.int/airpollution/en/.

15. Plusquin $M$, Guida F, Polidoro S et al. DNA methylation and exposure to ambient air pollution in two prospective cohorts. Environment International 2017; 108: 127-36. [Google Scholar/ PebMed].

16. Bioaerosols on the rise in the city. Cited 2019 April 29. Available from: https://www.thehindu.com/news/ cities/bangalore/bioaerosols-on-the-rise-in-the-city/ article25814416.ece.

17. Maggie Fox. Pollution can counteract exercise benefits, study finds. Health News. Cited 2018 Dec 29. Available from: https://www.nbcnews.com/health/health-news/ pollution-can-counteract-exercise-benefits-studyfinds-n826811.

18. Chris Smyth H. Air pollution on busy roads as bad as passively smoking 10 a day. Cited 2019 Jan 27. Available from: https://www.thetimes.co.uk/article/air-pollutionon-busy-roads-as-bad-as-passive-smoking-10-a-day$60 q 2$ pwdg.

19. Road rage. Cited 2019 April 26. Available from: https:// dictionary.cambridge.org/dictionary/english/road-rage.

20. Debroy S. Long hours spent on roads gives rise to stress, road rage and hypertension. The Times of India. Cited 2019 May 13. Available from: https://timesofindia. indiatimes.com/city/mumbai/long-hours-spent-onroads-give-rise-to-stress-road-rage-and-hypertension/ articleshow/65380194.cms.

21. Kylstra C. 10 things your commute does to your body. Cited 2019 April 29. Available from: http://time. com/9912/10-things-your-commute-does-to-yourbody/.

22. The effects of stress on your body. Cited 2019 Sep 10. Available from: https://www.healthline.com/health/ stress/effects-on-body\#1.

23. Emma Innes. Get stressed in traffic jams? Be warned. It could harm your mental health years later. Mail Online. Cited 2019 April 20. Available from: http://www. dailymail.co.uk/health/article-2303482/get-stressedtraffic-jams-be-warned-it-harm-mental-health-yearslater.html.

24. Pietrangelo $A$, Watson $S$. The effects of stress on your body. Cited 2019 July 15 . Available from: https://www. healthline.com/health/stress/effects-on-body\#5.

25. Alalool A, Alhashaikeh B, Ibrahim H et al. Traffic congestion \& long driving hours: Impact on stress, emotional and physical health among drivers in 
Sharjah. Health care, current reviews 2016. Primary Health Care 2017; 7: 3 (Suppl). Available from: https:// www.longdom.org/proceedings/traffic-congestion-long-driving-hours-impact-on-stress-emotional-andphysical-health-among-drivers-in-sharjah-8416.html.

26. Three things traffic congestion does to your brain. Metropia - driving a better city. Cited 2019 July 27. Available from: http://www.metropia.com/blog/threethings-traffic-congestion-does-your-brain. 